Published on Reviews in History (https://reviews.history.ac.uk)

\title{
INTERVIEW: Daniel Snowman talks to Peter Hennessy
}

Review Number: 1988

Publish date: Thursday, 15 September, 2016

Author: Peter Hennessy

Robert Shepherd

ISBN: 9781910376485

Date of Publication: 2016

Price: $£ 20.00$

Pages: 220pp.

Publisher: Haus Publishing

Publisher url: http://hauspublishing.com/non-fiction/reflections-conversations-with-politicians-by-peter-hennessy Place of Publication: London

Reviewer: Daniel Snowman

In the latest of our occasional Reviews in History podcast series, Daniel Snowman talks to Peter Hennessy about his background, career, influences and forthcoming book.

Peter Hennessy was Attlee Professor of Contemporary British History at Queen Mary, University of London. He spent 20 years in journalism and as a presenter of the BBC Radio 4's Analysis. He sits as an independent crossbench peer in the House of Lords.

Daniel Snowman is a writer, lecturer and broadcaster on social and cultural history.

Listen to the introduction here [2] OR to the entire interview here [3].

Source URL:https://reviews.history.ac.uk/review/1988

\section{Links}

[1] https://reviews.history.ac.uk/item/241396

[2] http://podcast.ulcc.ac.uk/accounts/SAScasts/ReviewsinHistory/SnowmanonHennesseyeditedintro.mp3

[3] http://podcast.ulcc.ac.uk/accounts/SAScasts/ReviewsinHistory/SnowmanonHennesseyeditedlong.mp3 